\title{
THE CAUSES OF AREA EFFECTS
}

\author{
A. J. CAIN and J. D. CURREY \\ Department of Zoology, University Museum, Oxford
}

Received 10.v.63

IN our paper describing and defining area effects in Cepaa nemoralis on the Marlborough Downs (Cain and Currey, I963a) we wrote, in connection with the distribution of $M^{3}$ producing the midbanded phenotype 00300 which is responsible for the principal area effect, "It would seem, then, that the most likely explanation for the situation described from the downs is that there is selection acting especially in certain downland areas to favour 00300 irrespective of what visual predation may be going on in these areas. Since on the Marlborough Downs there is this favouring of $M^{3}$ in one area, but in another very similar one $M^{3}$ is usually absent, it is possible that under extreme conditions, either the heterozygotes are at a disadvantage, or there are co-adaptations in the genotypes producing alternative optima with $M^{3}$ at I $\cdot 0$ or $0 \cdot 0$ ". Goodhart ( 1963 ) has now suggested that the area effects are the product not of local environmental selection as we concluded, but of co-adaptations of genotypes originating within small populations heavily affected by genetic drift or the founder principle. We are glad to take the opportunity of discussing this interesting suggestion.

Let it be granted that, as Goodhart postulates, C. nemoralis originally spread on the downs from a few very small and widely separated populations, in each of which a different co-adaptation of genotypes was produced by chance and thereafter determined the frequencies of the different morphs while the populations were spreading. There are three main possibilities for future events, supposing these populations to spread out and meet. Either (i) the co-adaptations achieved are insensitive to any variations encountered in the environment, or (ii) they are sensitive to them but not to the extent of breaking up the co-adaptations, or (iii) environmental selection will wholly determine their fate by actually breaking them up and remodelling the populations.

In the last case (iii), it is clear that environmental selection will now be determining all the frequencies, however they arose in the first place, any fortuitous co-adaptations being overridden. The result is therefore indistinguishable from determination by environmental selection from the beginning. In case (i), the differently co-adapted populations, being wholly insensitive to environmental differences, are effectively living in a uniform expanse of environment. But it is extremely unlikely that they will all be exactly equally successful competitively in the same environment. Consequently when they 
spread and meet, if as Goodhart suggests there is considerable inviability (or sterility) in the hybrids, one should invade the territory of the others and gradually replace them. If the hybrids are less inviable and some gene flow can take place, modifying the original populations, the same result will follow in the end, and there is a possibility that one of the modified forms might prove the best of all. Either way, with sufficient time, one set of co-adaptations should be found everywhere, which is manifestly not so on the Marlborough Downs. In case (ii), again the differently co-adapted populations will spread, but on meeting will prove of different success in different parts of the environment which in this example is not effectively uniform. The constitution of the different populations will not be determined by the environment (except in so far as some may be selected out altogether by competition) but the limits of their distributions will be, and this may be done by slight changes due to long gentle environmental gradients, not necessarily by heavy local selection. This would then produce a situation in which very slight environmental differences might be associated with strong area effects. If one population is favoured towards one end of an environmental gradient and another towards the other end, they will come to an equilibrium-distribution with the boundary between them no doubt fluctuating to some extent, and with its sharpness determined by the amount of inviability or infertility of the hybrids. The situation envisaged by Goodhart in which there are temporal fluctuations in some environmental factor acting over the whole area (such as long-term changes in general climate) will not produce an equilibrium as he states; it can at best only delay the elimination of one population by the other.

As Goodhart agrees, it is likely that the original populations on the Marlborough Downs have spread and been in contact for a very long time, perhaps more than a thousand years. The subfossil evidence for stability of area effects on the Marlborough Downs set out by us (1963a, unfortunately not referred to in our brief account, 1963b) has now been strengthened (Currey and Cain in preparation). We can therefore allow that boundaries of the area effects may be fluctuating to some extent, but nevertheless go on to consider what sort of pattern of distribution would be expected from the situation considered under case (ii). If the environmental gradient positioning two contiguous area effects is very gentle, the width of the hybrid zone will depend only on the degree of inviability of the hybrids relative to the two parental stocks-and on the speed at which individual snails can move, which is known to be very low (Murray, 1962; Goodhart, 1962). If the degree of inviability of the hybrids is very high, the zone will be extremely narrow from the moment of its formation at any point. If the inviability is comparatively low, the zone will be much wider, and while the populations are making contact may vary in width considerably from maximum width where equilibrium has been established to very narrow where meeting has only just occurred. 
When contact has been completed for some time, the zone should be of rather constant width all along. Temporary irregularities might occur if small and genetically different populations became included in the zone, but these also, unless constantly recruited from elsewhere, will be reduced to uniformity.

The most striking area effects on the Marlborough Downs are produced by fixation or absence of $M^{3}$ (producing o030o). A large triangular area saturated with $M^{3}$ touches at its apex a small area of violent transition which joins it to the apex of another area devoid of $M^{3}$. The space between the two main areas is itself very roughly triangular, broadening as one moves away from the area of violent transition, so that the populations of intermediate nature become much more widely distributed (Cain and Currey, I $963 a$, fig. 5). Such a zone of non-uniform width in an effectively uniform environment, if stable, can only be maintained between three distinct populations all contributing to the hybrid zone; but in this case there is no third population, the district on the third side of the zone being occupied by C. hortensis. In colour also (Cain and Currey, 1963a, fig. 6) the principal area of intermediate frequencies of brown, pink and yellow is not between the brown and yellow areas but projecting into a region of $C$. hortensis (Cain and Currey, 1963a, fig. 2). Local differences in hybrid inviability due to differences in the parental stocks will not be maintained indefinitely against gene-flow in the parental populations; and the only remaining agent that could produce a stable hybrid zone not of approximately constant width in a region of approximate uniformity as far as dispersal rates are concerned is differential environmental selection. Consideration of the actual patterns of morph frequencies on the Marlborough Downs, therefore, suggests that they do not provide, as Goodhart claims, as good an example of nonadaptive variation as any that could be expected to be found in natural populations not subject to experimental control, but on the contrary point rather clearly to the existence of environmental selection. If, however, the existence of environmental selection not related to the obvious features of the environment is admitted, then for all we know, it may be extremely strong.

Goodhart suggests that if in two areas each of which contains much the same large repertoire of ecological variation (e.g. grassland, hedgerow and beech wood) there are great differences in morph frequency which are associated only with the areas and not with the ecology, then it is difficult to believe that the genetical variation can have been determined ecologically. This is the sort of situation we have described from the Marlborough Downs; but the argument is not strong, as Goodhart points out. Dr M. H. Williamson has suggested to us that a comparison between the situation just described and that known to occur in the relative distribution of Cepea nemoralis and hortensis is profitable. These species are often found to occupy large contiguous areas on the downs to the virtual exclusion of each other. It is most $2 \mathrm{G} 2$ 
unlikely that this can be due to historical accident, as both species are often abundant and widespread and have probably co-existed on the downs for thousands of years. Hybrids are known to be extremely rare, and no hybrid zones like those postulated between differently co-adapted populations within nemoralis occur. The two species are found not infrequently to be co-existing in mixed populations, so that there is no direct antagonism between them. It is most unlikely that the two different species should be competitively equivalent, and there is evidence from sand dune colonies that they are indeed in competition. But the changeover from an area of nemoralis to one of hortensis on apparently uniform open downland may be extremely abrupt and involve thousands of individuals on either side, and yet be related to no obvious feature of the environment. This suggests very strongly that there are from the point of view of Cepea considerable differences of environment, which may be imperceptible to us, between areas obviously ecologically diversified. It happens that in the Marlborough district we have found a possible ecological explanation of the distributions of $C$. nemoralis and hortensis (Cain and Currey, 1963a), but elsewhere (e.g. on Salisbury Plain, Cain and Currey in preparation) they seem not to be readily explicable. Goodhart himself (r962) has stated that along a stretch of what he believes to be an effectively uniform environment there are considerable variations in the density of $C$. nemoralis; these suggest immediately that there can be ecological variation of importance to Cepea and of a kind not readily perceptible to a competent observer.

Our suggestion that local climatic differences, which are surely affecting the distribution of nemoralis and hortensis, may also have some bearing on area effects is certainly tentative. Goodhart considers that secular changes in climate since the early Neolithic have been greater than local differences at the present day, but this is unlikely. Differences between a steep north-facing slope and a south-facing one, between a convex hilltop and a frost-hollow, or perhaps even between the north face and south face of a tree trunk are at least comparable in magnitude with the mean climatic differences between Zone II of the Post-Glacial in Britain (c. I I, 0oo years BP) and the present, or even the present and the post-glacial optimum (Zone VII $a, c .6000$ years BP; see Godwin (1956) for a general account, and references in Cain and Currey (1963a) for topographical differences).

Goodhart also suggests that small area effects may be widespread and account for much of the large inter-colony variation in morph frequencies shown in hedgerow and rough herbage colonies in the Oxford district (Cain and Sheppard, 1954) where visual selection is known to be important. However, his assertion that hedgerows, or rough herbage, conform to a general type about as much as does mixed deciduous woodland is certainly incorrect. Hedgerows, for example, vary from what are effectively small deciduous woods to a thin line of quicksets on a bank covered with grass, and moreover, 
they are subject to considerable if infrequent disturbance when cut and layered. The greater variance in morph frequencies between hedgerow or rough herbage colonies as compared with those from oak woods or mixed deciduous woods is in fact an argument for the strength of visual selection in the Oxford district. This is not to say, of course, that some amount of difference between colonies in the Oxford district may not be due to historical accidents of some description.

Even if one agrees with Goodhart's general position, it seems from its consequences that some non-visual environmental selection must be acting on the Marlborough Downs, and the degree to which the area effects are maintained by co-adaptation is far from certain. It should also be pointed out that the sort of hybrid inviability he seems to postulate is remarkably strong; the situations envisaged are likely to lead to speciation, yet nemoralis is a single widespread form, not a superspecies broken up into a mosaic of allopatric species. In our opinion, the considerations given above point more to the probable importance of selection by the external environment than to the effects of chance happenings in the remote past, although these cannot be ruled out. There seem to be at least three main classes of selection acting in Cepra, namely some forms of non-visual selection maintaining the polymorphism, others tending to sway the resulting balance in different areas even to the point of destroying it, and visual selection also swaying the balance in different types of habitat but in relation to factors other than those producing the second class. As Clarke (1962) suggests, there may be also a class of visual selection acting to maintain the balance. The interaction of selective forces is complex, and seems to leave little scope for purely random effects.

Acknowledgments.-We are grateful to Dr G. B. Goodhart for discussing certain points, and to Mr E. R. Creed and Professor P. M. Sheppard for criticism of this paper.

\section{REFERENCES}

Cain, A. J., And currey, J. D. $1963 a$. Area effects in Cepaa. Phil. Trans. Roy. Soc. Lond., $246,1-8 \mathrm{I}$.

CAIN, A. J., AND CURREY, J. D. $1963 b$. Differences in interactions between selective forces acting in the wild on certain pleiotropic genes of Cepæa. Nature, 197, 4 II-4II.

CAin, A. J., AND sheppard, P. м. 1954. Natural selection in Cepea. Genetics, 39, 89-116.

CLARKE, B. C. 1962. Natural selection in mixed populations of two polymorphic snails. Heredity, 17,3 19-345.

GoDwIN, H. 1956. The history of the British flora. A factual basis for phytogeography. Cambridge, England : University Press.

GOODHART, c. B. 1962. Variation in a colony of the snail Cepea nemoralis (L.). 7. anim. Ecol., 3I, 207-237.

GOODHART, c. B. 1963. "Area effects" and non-adaptive variation between populations of Cepra. Heredity, $18,459-465$.

MURRAY, J. J. 1962. Factors affecting gene frequencies in some populations of Cepaa. D.Phil. thesis, University of Oxford. 